\title{
Regional evidence of modulation of cardiac adiponectin level in dilated cardiomyopathy: pilot study in a porcine animal model
}

\author{
Chiara Caselli ${ }^{1}$, Vincenzo Lionetti ${ }^{2}$, Manuela Cabiati ${ }^{1}$, Tommaso Prescimone ${ }^{1}$, Giovanni D Aquaro ${ }^{3}$, \\ Virginia Ottaviano ${ }^{4}$, Fabio Bernini ${ }^{3}$, Letizia Mattii ${ }^{5}$, Silvia Del Ry ${ }^{1}$ and Daniela Giannessi ${ }^{*}$
}

\begin{abstract}
Background: The role of systemic and myocardial adiponectin (ADN) in dilated cardiomyopathy is still debated. We tested the regulation of both systemic and myocardial ADN and the relationship with AMP-activated protein kinase (AMPK) activity in a swine model of non-ischemic dilated cardiomyopathy.

Methods and results: Cardiac tissue was collected from seven instrumented adult male minipigs by pacing the left ventricular (LV) free wall (180 beats/min, 3 weeks), both from pacing (PS) and opposite sites (OS), and from five controls. Circulating ADN levels were inversely related to global and regional cardiac function. Myocardial ADN in PS was down-regulated compared to control $(p<0.05)$, yet ADN receptor 1 was significantly up-regulated ( $<<$ 0.05). No modifications of AMPK were observed in either region of the failing heart. Similarly, myocardial mRNA levels of PPARY, PPARa, TNFa, iNOS were unchanged compared to controls.

Conclusions: Paradoxically, circulating ADN did not show any cardioprotective effect, confirming its role as negative prognostic biomarker of heart failure. Myocardial ADN was reduced in PS compared to control in an AMPK-independent fashion, suggesting the occurrence of novel mechanisms by which reduced cardiac ADN levels may regionally mediate the decline of cardiac function.
\end{abstract}

Keywords: Adiponectin receptors, Heart failure, Animal models, AMPK, Adiponectin

\section{Background}

Adiponectin (ADN) is an adipocyte-derived protein that is abundantly present in plasma [1] and is also expressed in cardiomyocytes [2] and endothelial cells [3]. Two ADN receptors, AdipoR1 and AdipoR2, have been characterized: AdipoR1 is abundantly expressed in skeletal muscle, whereas AdipoR2 is predominantly expressed in the liver [4]. T-cadherin, an additional ADN receptor, is expressed in cardiomyocytes and is involved in ADNmediated cardioprotection [5]. The remodeling of the failing heart has induced a number of investigators to test the hypothesis that modulation of myocardial metabolism might prove therapeutically advantageous [6].

\footnotetext{
* Correspondence: danielag@ifc.cnr.it

'Consiglio Nazionale delle Ricerche (CNR), Institute of Clinical Physiology,

Laboratory of Cardiovascular Biochemistry, Pisa, Italy

Full list of author information is available at the end of the article
}

Potential downstream effectors of $\mathrm{ADN}$ receptors include AMP-activated protein kinase (AMPK) and peroxisome proliferator-activated receptor- $\alpha$ (PPAR- $\alpha)$. AMPK is considered an energy-sensing enzyme that on stimulation enhances glucose use and fatty acid oxidation, whereas PPAR- $\alpha$ is a key nuclear transcription factor, regulating expression of genes involved in fatty acid uptake and use [7]. It was recently shown that cardiac ADN and its receptors are elicited by PPAR- $\gamma$ activation, confirming the role of ADN in maintaining myocardial energy homeostasis [2].

In addition, cardioprotective effects of ADN have been well-demonstrated [8-11]. Many clinical studies have shown that $\mathrm{ADN}$ is inversely correlated with an increased cardiovascular risk, and hypo-adiponectinemia has been established as an independent cardiovascular risk factor in coronary artery disease [12-17]. Similarly, in patients with dilated cardiomyopathy (DCM) without 
overt heart failure (HF), ADN down-regulation is associated with severe endothelial/microvascular dysfunction [18]. Conversely, in patients with overt HF, ADN levels are increased [19] in presence of an increased mortality risk [20]. Further investigation of the autocrine/paracrine role of the cardiac ADN system in the failing heart at different stages could aid in understanding the "ADN paradox" [21]. This issue is still debated and little information is available.

The main aim of our study was to assess the regional modulation of ADN system in a clinically relevant model of non-ischemic HF, both at cardiac and systemic circulating levels. For this purpose, the myocardial expression of ADN, ADN receptors and modulators was determined in an experimental model of LV-pacing induced HF [22] and compared with healthy myocardium. ADN signaling was investigated to address myocardial remodeling, inflammation and metabolic process in different regions of the non-ischemic failing left ventricle (LV) regarding biochemical and functional patterns.

\section{Methods}

\section{Experimental animal protocol}

A total of twelve male adult minipigs (30-40 kg bw) were studied. Non-ischemic HF was induced in seven animals by epicardial pacing of the left ventricle (LV) at 180 beats/min for 3 weeks. Minipigs were sedated with a cocktail of tiletamine hydrochloride and zolazepam hydrochloride $(8 \mathrm{mg} / \mathrm{kg} \mathrm{im})$ and premedicated with atropine sulfate $(0.1 \mathrm{mg} / \mathrm{kg} \mathrm{im})$. General anesthesia was subsequently induced with propofol $(2-4 \mathrm{mg} / \mathrm{kg}$ iv) and maintained with $1-2 \%$ isoflurane in $60 \%$ air and $40 \%$ oxygen. A thoracotomy was performed in the left fifth intercostal space, then a catheter was inserted in the descending thoracic aorta and a solid-state pressure gauge (Konigsberg Instruments) inserted in the left ventricle (LV) through the apex. A Doppler flow probe (Craig Hartley) was placed around the left anterior descending coronary artery, and a screw-type unipolar, epicardial pacing lead (5071 IS-1 UNI; Medtronic, Inc) was attached to the LV free wall, approximately $3 \mathrm{~cm}$ distal to the atrioventricular margin. A programmable pacemaker (PREVAILTM, Medtronic, Inc) was implanted in a subcutaneous pocket. Baseline measurements were taken after 7-10 days of post-surgical recovery. Pigs were considered to be in severe HF when left ventricular end-diastolic pressure was $\geq 20 \mathrm{mmHg}$. Hemodynamic and magnetic resonance imaging (MRI, 1.5 Tesla) measurements were performed at baseline and after 21 days of pacing in sedated animals as previously described $[22,23]$. The minipigs were finally sacrificed by injecting saturated $\mathrm{KCl}$ solution intravenously after deep sedation with $3.3 \mathrm{mg} / \mathrm{kg}$ of propofol. The heart was quickly removed and cardiac tissue samples immediately placed in ice-cold RNAlater (Qiagen, Germany) and formalin solution, neutral buffered, 10\% (Sigma-Aldrich, St. Louis, $\mathrm{MO}$, USA) stored at $-80^{\circ} \mathrm{C}$. For our analysis, we selected $\mathrm{LV}$ regions surrounding the site of pacing, i.e., the anterior and anterior-lateral regions, called pacing site (PS), and remote from the pacing site, i.e., the inferior and septal-inferior regions, called opposite site (OS). Five healthy minipigs were also studied as controls. Before and after the procedure, peripheral blood samples were withdrawn from animals in tubes containing EDTA $(1 \mathrm{mg} / \mathrm{mL})$ and plasma samples were stored at $-20^{\circ} \mathrm{C}$ in aliquots. Animal instrumentation and experimental protocols were approved by the Animal Care Committee according to Italian legislation, following the National Institute of Health publication Guide for Care and Use of Laboratory Animals.

\section{Cardiac MRI measurements}

Cine-MRI images were acquired with a 1.5 Tesla MRI scanner (Signa Excite HD, GE Medical Systems, Waukesha, WI, USA) in sedated animals with continuous infusion of midazolam (0.1 mg•kg-1•h iv) at spontaneous heart rate. As previously described by us and by others [23,24] global (end-diastolic volume, end-systolic volume, and ejection fraction) LV parameters of contractile function were analyzed in pacing-induced HF with a commercially available research software package (Mass Analysis, Leyden, The Netherlands). To regionally assess the presence of tissue fibrosis, gadolinium-delayed contrast-enhanced images were acquired in two-dimensional segmented inversion recovery-prepared gradient echo sequence $10 \mathrm{~min}$ after administration of contrast agent Gd-DTPA $(0.2 \mathrm{mmol} /$ $\mathrm{kg}$ iv) in short-axis views.

\section{RNA and protein extraction}

Total RNA and proteins were extracted from LV samples by TRI-REAGENT (MRC, Inc, Cincinnati, OH, USA), as previously described [25]. Total RNA was purified by RNeasy Kit and DNase I (Qiagen, Germany). The extracted RNA was solubilized in RNase-free water and quantified spectophotometrically at $260 \mathrm{~nm}$. The ratio of O.D. values at $260 \mathrm{~nm}$ and $280 \mathrm{~nm}$ provided an estimate of RNA purity. For each sample, the RNA integrity was evaluated by electrophoresis in a $1.5 \%$ agarose gel. The proteins extracted from the organic phase were quantified by Lowry protein assay, using bovine serum albumin as standard.

\section{mRNA expression analysis (RT-PCR)}

For each sample, $5 \mu \mathrm{g}$ of total RNA were reverse transcribed to cDNA by iScript cDNA Synthesis Kit (Biorad, Hercules, CA, USA) in $100 \mu \mathrm{L}$ of total reaction volume, according to the manufacturer's instructions. The expression of ADN, AdipoR1, AdipoR2, T-cadherin, brain natriuretic peptides (BNP), tumor necrosis 
factor (TNF)- $\alpha$, inducible nitric oxide synthase (iNOS), were performed using specific primers and conditions (Table 1). All PCR reactions were performed in a 20- $\mu \mathrm{l}$ total volume, containing $0.5 \mathrm{U}$ of $\mathrm{Taq}$ polimerase (Qiagen, Germany), deoxyribonucleotide triphosphate (dNTP) $0.4 \mathrm{mM}, \mathrm{MgCl} 21.5 \mathrm{mM}$ and forward and reverse primers, $200 \mathrm{nM}$ each. To avoid the errors related to the common practice of using only one control gene, the three most stable reference genes selected from different abundance and functional classes in porcine cardiac tissue [26], glyceraldehyde 3-phosphate dehydrogenase (GAPDH), hypoxanthine phosphoribosyltransferase 1 (HPRT-1) and TATA binding protein (TBP), were evaluated using specific primers and specific PCR conditions (Table 1) and their geometric mean was used as normalization factor [27]. PCR products were separated on 1.5\% agarose gel and stained with GelStarNucleic Acid Gel Stain (Cambrex East Rutherford, NJ, USA). Pictures of resulting gels were taken with digital camera and image analysis was performed by QuantityOne Software (Biorad).

\section{Western blotting}

Total proteins obtained from cardiac tissue or plasma samples were subjected to western blot analysis after sodium dodecyl sulfate-polyacrylamide gel electrophoresis (SDS-PAGE), under reducing and denaturating conditions. After boiling at $95^{\circ} \mathrm{C}$ for $5 \mathrm{~min}$, samples $(70 \mu \mathrm{g}$ of total protein or $2 \mu \mathrm{L}$ of plasma per lane) were subjected to SDS-PAGE on $10 \%$ polyacrylamide gel and then transferred to polyvinylidene fluoride (PVDF) membrane for ADN and nitrocellulose membrane for phosphoAMPK $\alpha$ and AMPK $\alpha$. Nonspecific binding was blocked by incubation with $5 \%$ nonfat dry milk for $3 \mathrm{~h}$. The membranes were incubated overnight at $4^{\circ} \mathrm{C}$ with primary antibody against ADN (1:2000, Millipore, Billerica, MA, USA); AMPKa (1:1000, Cell Signaling Technologies, Boston, MA, USA) and phospho-AMPK $\alpha(1: 1000$, Cell Signaling Thecnologies). After washing, the membranes were incubated with anti-rabbit biotinilated (1:20000, Enzo Life Sciences International, Plymouth Meeting, PA, USA) or anti-mouse biotinilated (1:10000, Enzo Life Sciences International) for $1 \mathrm{~h}$ at room temperature and

Table 1 Sequence of RT-PCR primer pairs for analyzed genes

\begin{tabular}{|c|c|c|c|c|}
\hline Primer & GenBank & Sequence & $\mathrm{Ta},{ }^{\circ} \mathrm{C}$ & Cycles, $\mathrm{n}$ \\
\hline$\overline{A D N}$ & \multirow[t]{2}{*}{ EF601160.1 } & Forward: ATCTGGAGTGACTGGGGTTG & \multirow[t]{2}{*}{61} & \multirow[t]{2}{*}{36} \\
\hline $202 b p$ & & Reverse: TTTGCCAGTGGTGACATCAT & & \\
\hline AdipoR1 & \multirow[t]{2}{*}{ AB527058.1 } & Forward: AACCCACCCAAAGCTGAAGA & \multirow[t]{2}{*}{58} & \multirow[t]{2}{*}{29} \\
\hline $334 b p$ & & Reverse: CTGAGCATGGTCAAGATTCC & & \\
\hline AdipoR2 & \multirow[t]{2}{*}{ NM_001007192 } & Forward: GCCTGGGGATCTTITATATGTTTC & \multirow[t]{2}{*}{53} & \multirow[t]{2}{*}{34} \\
\hline $650 \mathrm{bp}$ & & Reverse: GCCGATCATGAAACGAA & & \\
\hline$\overline{T-C A D}$ & \multirow[t]{2}{*}{ NM_001109945.1 } & Forward: CCCGGGCAGAGCTTCGAAAT & \multirow[t]{2}{*}{64} & \multirow[t]{2}{*}{25} \\
\hline $217 b p$ & & Reverse: GGTAGAAAACCGGGCCCTCG & & \\
\hline PPAR-a & \multirow[t]{2}{*}{ NM_001044526.1 } & Forward: TCGCGGGAAAGGCCAGCAAT & \multirow[t]{2}{*}{70} & \multirow[t]{2}{*}{27} \\
\hline $431 b p$ & & Reverse: GTCGTCCAGCTCCAGCGCATT & & \\
\hline PPAR- $\gamma$ & \multirow[t]{2}{*}{ DQ437884.1 } & Forward: AGGAGCATAGCAAAGAGGTGGCC & \multirow[t]{2}{*}{70} & \multirow[t]{2}{*}{32} \\
\hline $391 b p$ & & Reverse: AGCAAACCTGGGCGGTCTCCA & & \\
\hline$\overline{B N P}$ & \multirow[t]{2}{*}{ M25547 } & Forward: GTGCTCCTGCTCCTGTTCTT & \multirow[t]{2}{*}{61} & \multirow[t]{2}{*}{35} \\
\hline $451 b p$ & & Reverse: TCCCAGGCTTCTGTGAGG & & \\
\hline iNOS & \multirow[t]{2}{*}{ NM_001143690.1 } & Forward: GAGGGCAGCCAAGGCCCAAG & \multirow[t]{2}{*}{65} & \multirow[t]{2}{*}{35} \\
\hline $264 b p$ & & Reverse: GGCCAGCTTTCGGAGCAGCA & & \\
\hline TNF-a & \multirow[t]{2}{*}{ EU682384.1 } & Forward: ATCGGCCCCCAGAAGGAAGAC & \multirow[t]{2}{*}{64} & \multirow[t]{2}{*}{33} \\
\hline $351 b p$ & & Reverse: GATGGCAGAGAGGAGGTTGAC & & \\
\hline$\overline{\text { GAPDH }}$ & \multirow[t]{2}{*}{ AF017079 } & Forward: ACCACAGTCCATGCCATCAC & \multirow[t]{2}{*}{60} & \multirow[t]{2}{*}{30} \\
\hline $451 b p$ & & Reverse: TCCACCACCCTGTTGCTGTA & & \\
\hline HPRT1 & \multirow[t]{2}{*}{ DQ178126 } & Forward: CCGAGGATTTGGAAAAGGT & \multirow[t]{2}{*}{60} & \multirow[t]{2}{*}{30} \\
\hline $181 \mathrm{bp}$ & & Reverse: CTATTTCTGTTCAGTGCTTTGATGT & & \\
\hline TBP & \multirow[t]{2}{*}{ DQ178129 } & Forward: GATGGACGTTCGGTTTAGG & 60 & 30 \\
\hline $124 b p$ & & Reverse: AGCAGCACAGTACGAGCAA & & \\
\hline
\end{tabular}

Adiponectin (ADN), AdipoR1, AdipoR2, T-cadherin (T-CAD), peroxisome proliferator-activated receptor (PPAR)- $\alpha$, PPAR- $\gamma$, brain natriuretic peptides (BNP), inducible nitric oxide synthase (iNOS), tumor necrosis factor (TNF)-a, glyceraldehyde 3-phosphate dehydrogenase (GAPDH), hypoxanthine phosphoribosyltransferase 1 (HPRT-1) and TATA binding protein (TBP). 
then, to amplify the signal, with horseradish peroxidaseconjugated streptavidin (1:2000, Biorad) for $30 \mathrm{~min}$ at room temperature. Sample loading was normalized by immunoblotting with anti-tubulin polyclonal antibody (1:500, Serotec, Oxford, UK). Proteins were visualized by colorimetric reaction using opti-4CN, (Biorad) and analyzed using QuantityOne Software (Biorad).

\section{Histochemistry and immunohistochemistry}

Formalin-fixed tissue specimens were embedded in paraffin. Five-micron-thick sections were cut and serially mounted on glasses. Sections were stained with hematoxilin and eosin stain and van Gieson's counterstain, to detect myocardial collagen deposits. Immunohistochemical analysis was performed to detect ADN. Briefly, sections were treated as follows: microwave antigen retrieval (700 $\mathrm{W}$ for $7 \mathrm{~min}$, twice in $10 \mathrm{mM}$ sodium citrate, $\mathrm{pH} 6.0$ ); hydrogen peroxide ( $3 \%$ in PBS $1 \mathrm{X}$ ) to block endogenous peroxidase and normal goat serum (10\% in PBS $1 \mathrm{X})$ to block non-specific bindings. ADN was detected by incubation overnight at $4{ }^{\circ} \mathrm{C}$ with the primary antibody (1:500, Millipore). Antibodies were diluted in PBS containing $0.1 \%$ goat serum and $0.1 \%$ TRITON. Sections were sequentially incubated with biotinylated anti-rabbit anti-serum (1:500, Enzo Life Sciences International), horseradish peroxidase-streptavidin complex (1:1000, Biorad), 3,3\$-diaminobenzidine tetrahydrocloride (DAB). Specimens were counterstained with hematoxylin (1:30), mounted with DPXÒ mountant for histology (Fluka, Buchs, Switzerland) and examined by light microscope. Negative controls were obtained by using secondary goat serum (1:100).

\section{Circulating and cardiac TNF-a measurement}

Arterial blood samples were collected during the imaging acquisition. Plasma levels as well as myocardial concentrations of porcine TNF- $\alpha$ were measured in duplicate by a specific ELISA kit (Thermo Scientific/Pierce, Rockford, IL, USA), with an assay range of $31.3-2000 \mathrm{pg} / \mathrm{mL}$ and a sensitivity $<5.0 \mathrm{pg} / \mathrm{mL}$.

\section{Statistical analysis}

Data are reported as media \pm SEM. Statistical comparisons were performed between PS, OS and controls by statistical software (SPSS 16.0 for Mac, Chicago, IL, USA). Differences between groups were compared by ANOVA followed by the Fisher post hoc test. A two-tailed P-value $<0.05$ was considered statistically significant.

\section{Results}

\section{Global and regional LV function}

Hemodynamic and MRI parameters of HF animals are reported in Table 2. All animals displayed the typical alterations of HF, including significant reduction of LV
Table 2 Global and regional LV function

\begin{tabular}{lll}
\hline & Baseline & $\mathbf{3}$ weeks of LV pacing \\
\hline Heart Rate, bpm & $94 \pm 6$ & $122 \pm 8^{*}$ \\
\hline MAP, mmHg & $109 \pm 8$ & $77 \pm 8.4^{*}$ \\
\hline LVEDP, mmHg & $5.5 \pm 3.04$ & $20.5 \pm 6^{*}$ \\
\hline LV dP/dtmax, mmHg/s & $2400 \pm 220$ & $1388 \pm 188^{*}$ \\
\hline LV EDV, ml & $65 \pm 5$ & $85 \pm 7.2^{*}$ \\
\hline LV ESV, ml & $15 \pm 3.4$ & $54.4 \pm 7.6^{*}$ \\
\hline LV EF, \% & $76.9 \pm 2$ & $36 \pm 1.8^{*}$ \\
\hline LV ESWT (PS), \% & $63 \pm 3.2$ & $5 \pm 1.2^{*}$ \\
\hline LV ESWT (OS), \% & $62 \pm 2.5$ & $40 \pm 1.8^{*}$
\end{tabular}

Values are means \pm SE. MAP, mean arterial pressure; LVEDP, left ventricular end diastolic pressure; EDV, end diastolic volume; ESV, end systolic volume; EF, ejection fraction; ESWT end systolic wall thickening; PS, pacing site; OS, opposte site. $n=7$.

* vs Baseline, $p<0.05$.

ejection fraction (LVEF) compared to healthy animals and increase of LV end-diastolic pressure (LVEDP), which reached $20 \pm 6 \mathrm{mmHg}$ after $21 \pm 2$ days of pacing. This is considered a stage of severe, although not terminal, HF [22].

\section{Circulating and cardiac ADN}

Circulating ADN levels measured by Western blotting increased significantly $(\mathrm{p}=0.031)$ in pigs after 21 days of pacing (Figure 1A).

The presence of ADN in cardiac muscle was checked by RT-PCR, western blotting and immunohistochemistry. ADN mRNA expression was downregulated in HF cardiac samples (Figure 1B), and it was significantly lower in PS compared to controls $(\mathrm{p}=0.041)$. As showed in Figure $1 \mathrm{C}$, myocardial $\mathrm{ADN}$ protein expression was very low. Similarly, ADN was weakly detected by immunohistochemistry in extracellular matrix surrounding vessel walls of PS, whereas no signal was detected in histological section of LV samples from OS and healthy animals (Figure 1D).

\section{ADN receptors}

mRNA expression of ADN receptors in cardiac muscle was determined by RT-PCR (Figure 2). As expected, in porcine heart AdipoR1 was expressed more than AdipoR2, as shown by the lower number of PCR cycles used to obtain the right number of cDNA copies in RT-PCR analysis (Table 1). AdipoR1 was significantly upregulated in PS when compared to OS ( $\mathrm{p}=0.044)$ and controls $(\mathrm{p}=0.024)$ and showed a negative correlation with ADN mRNA expression $(\mathrm{r}=-0.717, \mathrm{p}=0.001)$. Myocardial AdipoR2 and T-cadherin mRNA expression in failing heart was unchanged compared to control. A positive correlation between the AdipoRs was observed $(\mathrm{r}=0.582, \mathrm{p}=0.009)$. 


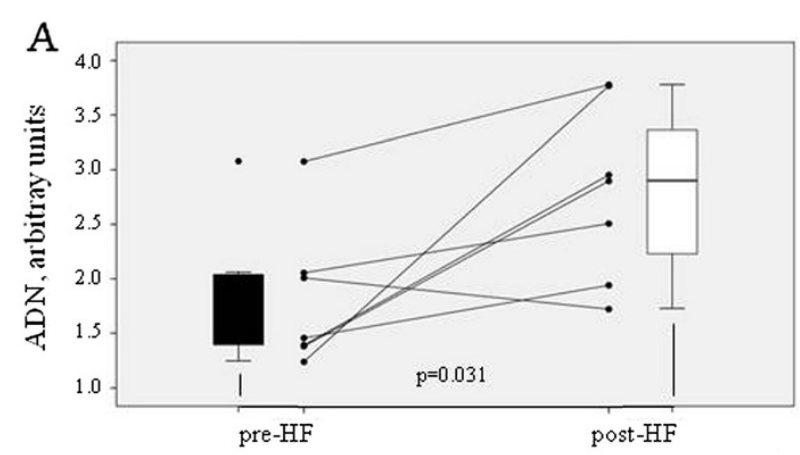

B

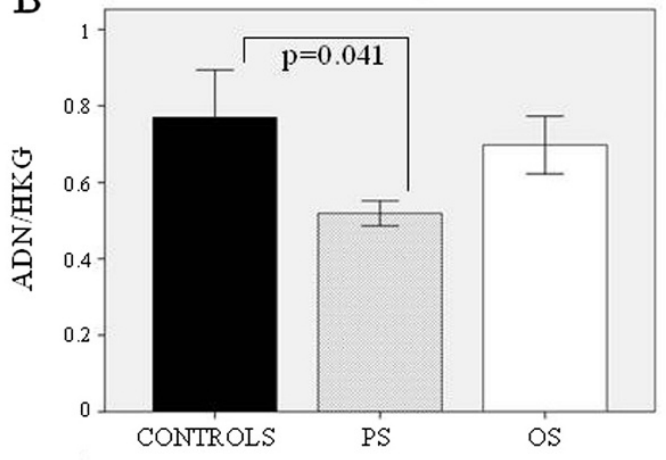

C

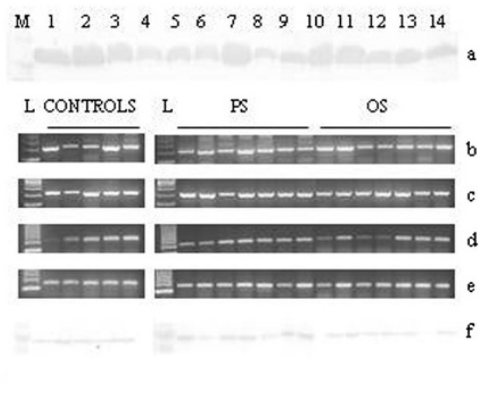

$\mathrm{D}$

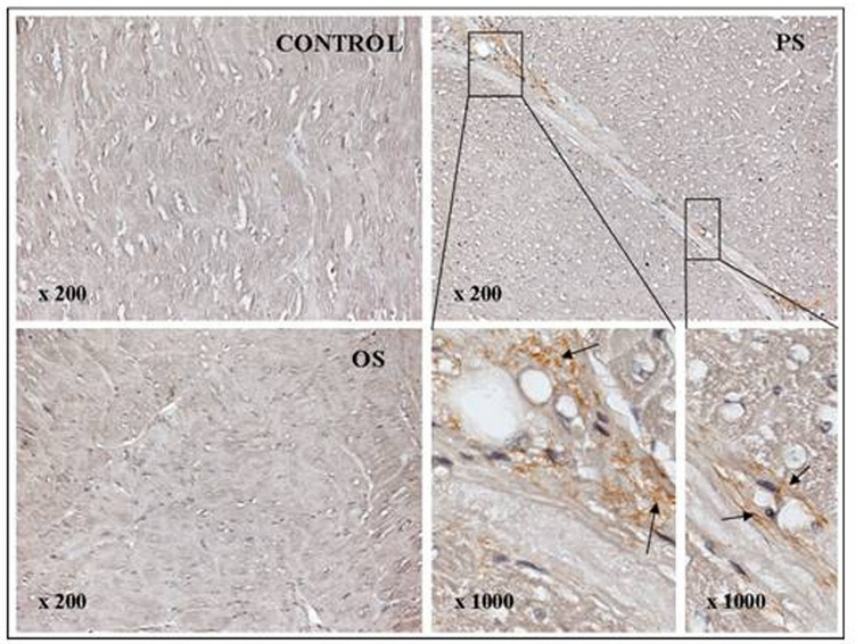

Figure 1 ADN presence in both plasma and cardiac tissue. A) Circulating levels of ADN measured by Western Blotting before the beginning of the experimental protocol and after 21 days of pacing induction $(n=7)$; B) ADN expression at mRNA level from PS, OS and controls; C) relative blots of circulating levels of ADN (a); mRNA expression of ADN (b) as well as housekeeping genes, GAPDH (c), HPRT-1 (d), TBP (e) measured by RT-PCR and immunoblots of ADN by Western blot (f); $\mathbf{D})$ representative immunostaining of ADN from heart sections showing the extra-cellular localization of ADN in peri-vascular tissue of PS.

\section{$A D N$ regulation}

To understand the mechanism underlying ADN system modification, mRNA expression of PPAR $\gamma$, an upstream $\mathrm{ADN}$ regulator [8], was determined in each region, but no changes compared to control were observed in PS and OS (Figure 3A). To investigate the relationship between the inflammatory process and ADN level in cardiac tissue, TNF- $\alpha$ expression was measured in both cardiac tissue and peripheral circulation. Myocardial TNF- $\alpha$ level in HF animals did not show any significant change compared to controls at both mRNA (Figure 3B) and protein expression $(7.82 \pm 2.04 \mathrm{pg} / \mathrm{mg}$ of total protein in PS, $8.85 \pm 2.36$ in OS, $8.53 \pm 2.40$ in controls, $\mathrm{p}=\mathrm{ns}$ ). TNF- $\alpha$ was not detected in peripheral 


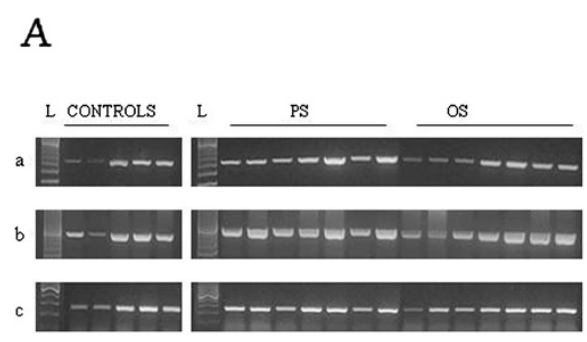

C

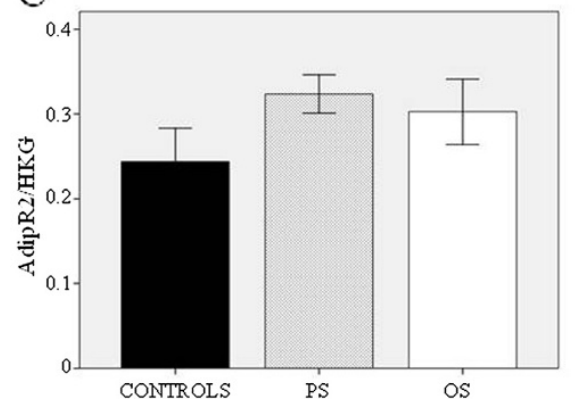

B

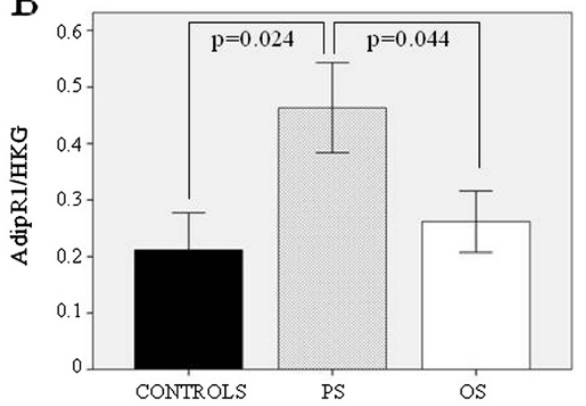

$\mathrm{D}$

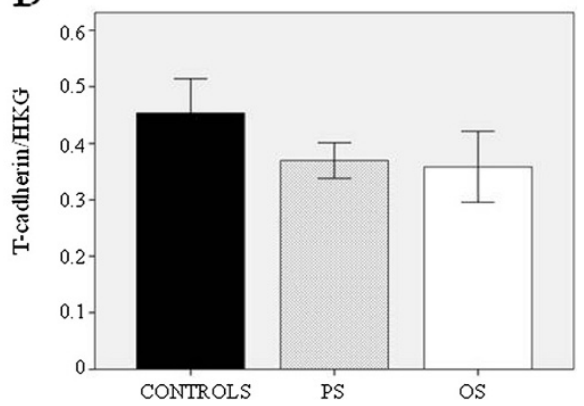

Figure 2 ADN receptors in cardiac tissue from both PS and OS as well as in control hearts. A) relative blots of AdipoR1 (a), AdipoR2 (b) and T-cadherin (c) RT-PCR products; B) mRNA expression of Adipo R1; C) AdipoR2, and D) T-cadherin.

circulation either at baseline or at 21 days of sustained pacing. No inflammatory cells were detected in either region of the failing heart as nor in controls (Figure 3E), confirming the lack of inflammation. Finally, we found that $\mathrm{ADN}$ is inversely correlated with $\mathrm{BNP}(\mathrm{P}<0.05)$ (Figure 3D).

\section{ADN signaling}

Figure 4A shows the results of RT-PCR and WB analysis performed in healthy and failing hearts. To explore the relationship between $\mathrm{ADN}$ and metabolism as well as apoptotic pathways, the regional activation of AMPK $\alpha$ and PPAR $\alpha$ expression were investigated. As shown in Figure 4B, the myocardial expression and phosphorylation of $\mathrm{AMPK} \alpha$ showed no changes in failing hearts compared to controls. In addition, the expression of PPAR $\alpha$ (Figure $4 \mathrm{C}$ ) and iNOS in HF PS and OS was equal to that in controls.

\section{Cardiac remodeling}

Histological measures in HF PS and OS revealed no difference in collagen deposits compared to controls, yet a weak positive stain was detected in the perivascular area of the pacing site (Figure 4E), confirming the absence of gross myocardial fibrosis in presence of severe regional contractile failure [22].

\section{Discussion}

We investigated the myocardial ADN pathway in a clinically relevant animal model of non-ischemic dilated cardiomyopathy. The main findings of our study are: first, increased circulating ADN levels in HF minipigs did not affect myocardial AMPK expression and activity, nor PPAR $\alpha$ expression; second, sustained high-rate LV pacing caused a significant reduction of ADN level and increased AdipoR1 level in PS, but not in OS; third, regional ADN down-regulation was related to severe contractile impairment, yet the key regulators of altered cardiac metabolism, inflammation and remodeling were unchanged compared to control hearts.

High circulating ADN levels have been reported repeatedly in HF [19-21,28] and several mechanisms have been utilized to explain this increase. Recent studies have reported that natriuretic peptides enhance ADN production via the cGMP pathway, by human adipocytes both in vitro and in vivo in patients with HF $[29,30]$. We have previously described that BNP and CNP expression increased in adult minipigs after 21 days of $\mathrm{LV}$ pacing [25]. It is well-known that natriuretic peptides are secreted almost exclusively by cardiac tissue and their levels are increased in patients with HF [31]. It has been hypothesized that the ADN increase could be a compensatory effect in order to restore metabolic homeostasis, due to its anti-inflammatory and insulin-sensitizing effects [32,33]. Abnormalities in glucose regulation, such 


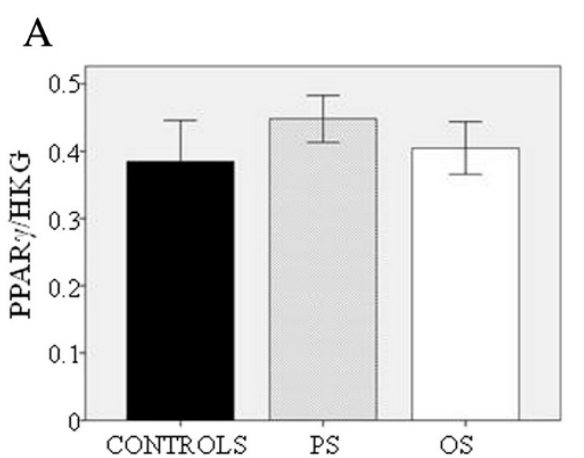

$\mathrm{C}$

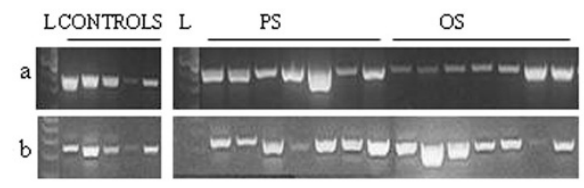

B

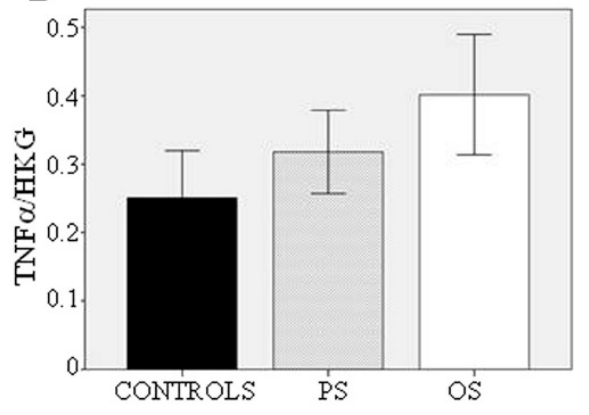

$\mathrm{D}$

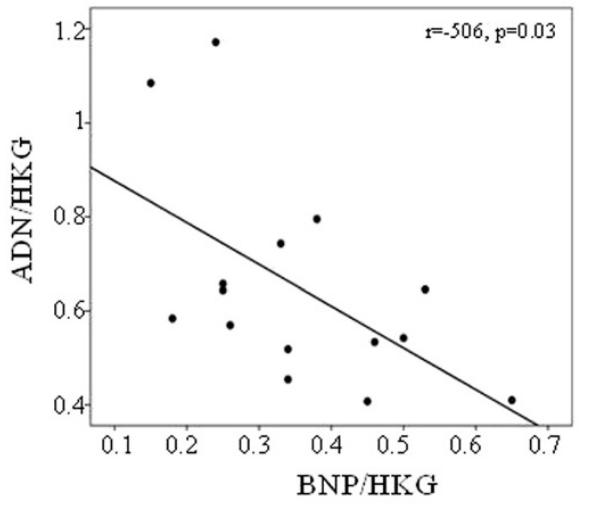

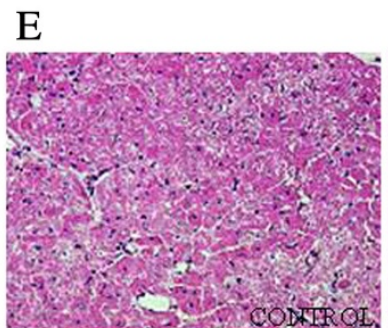
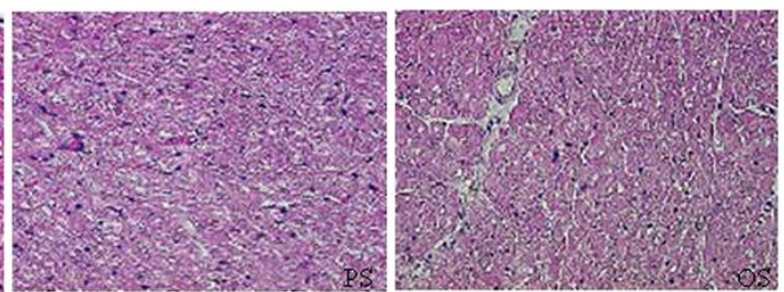

Figure 3 ADN regulation. A) mRNA expression of PPARy and $\mathbf{B}$ ) TNFa in PS, OS and controls $\mathbf{C}$ )as well as relative blots of RT-PCR products $\mathbf{D}$ ); relationships between ADN and BNP mRNA expression; $\mathbf{E}$ ) representative immunostaining of hematoxilin and eosin stain from heart sections.

as impaired glucose tolerance and insulin resistance, have been shown to correlate with HF severity [34]. In our animal model, we previously found that plasma insulin concentration was significantly higher in HF compared to control in presence of homogenous LV increase of glucose uptake [22]. In our study, no change was observed in AMPK activity and PPAR $\alpha$ expression in presence of a marked reduction of global and regional LV function. The lack of cardiac activation of the ADN downstream molecules could suggest that their associated cardiac effects are not related to high ADN plasma levels. This may agree with previous studies reporting an association between high levels of ADN in HF and severity as well as increased mortality, indicating for ADN a role as prognostic biomarker of HF [20,21]. Based on these findings, a "functional ADN resistance" in $\mathrm{HF}$ at the receptor level has been hypothesized. This resistance could determine an attenuated ADN response during the progression of HF [21], as recently observed at the level of skeletal muscle in chronic HF [35]. In this paper, a strong positive correlation between AdipoR1 and PPAR $\alpha$ /AMPK gene expression was found. In our study, we found an increased expression of AdipoR1 in the HF pacing site in presence of myocardial ADN mRNA down-regulation, yet PPAR $\alpha / A M P K$ gene expression and AMPK activity were not significantly different from healthy heart. As to T-cadherin, a physical association of ADN with T-cadherin is a prerequisite for ADN's physiological activity in the heart [5]; thus, the reduction of T-cadherin mRNA expression in failing heart, although not significant, could support the reduced activity of ADN/AdipoR system in this condition. 


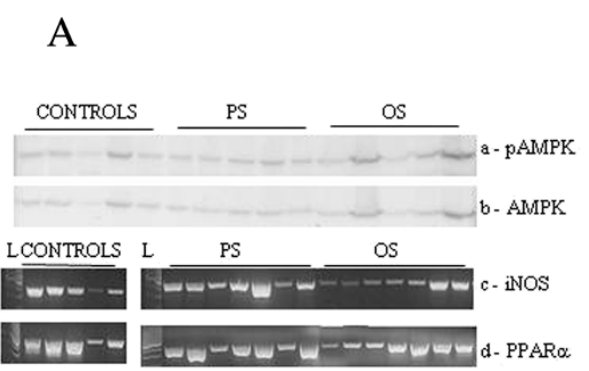

$\mathrm{C}$

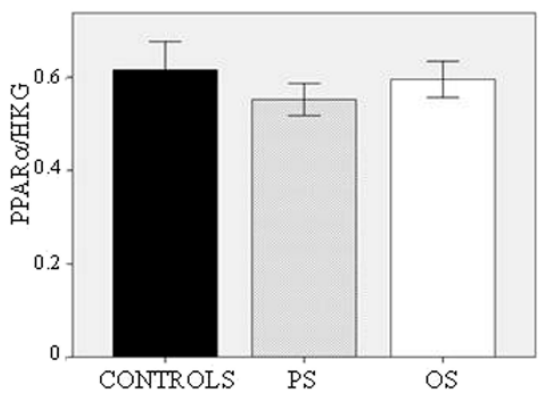

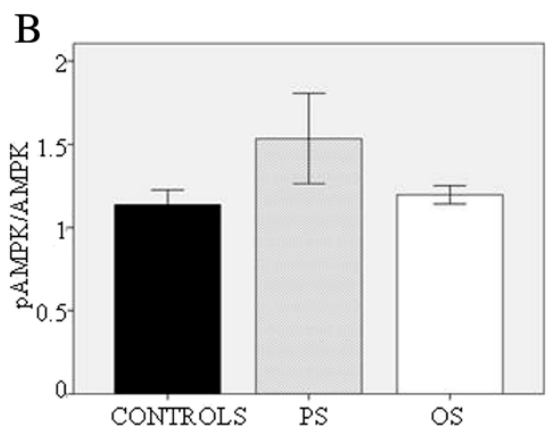

$\mathrm{D}$

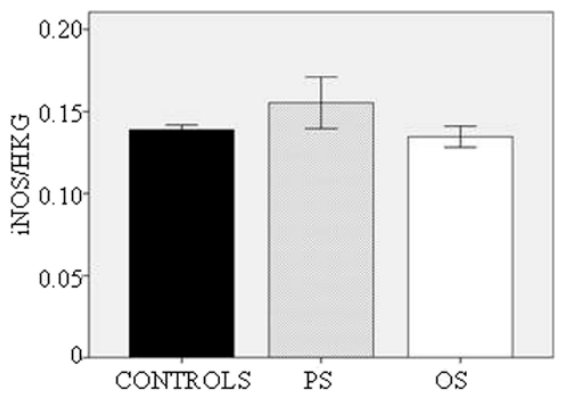

$\mathrm{E}$

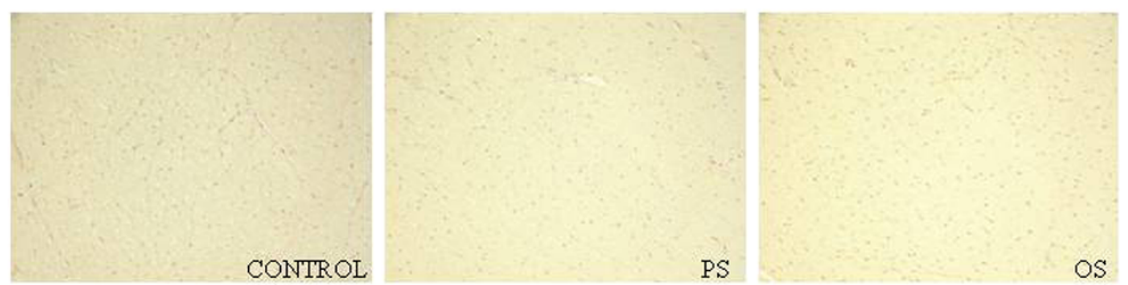

Figure 4 Cardiac molecular pathways involved in ADN signaling. A) relative immunoblots of pAMPK and AMPK as well as mRNA expression of PPARa and iNOS; $\mathbf{B}$ ) the ratio of phospho-AMPK and AMPK in PS, OS and controls; C) mRNA expression of PPARa; D) mRNA expression of iNOS; E) van Gieson's staining of heart section from PS, OS and controls.

The different behavior of systemic and cardiac ADN expression (Figure 1) as well as the presence of a regional variation in myocardial tissue after pacing are in tune with the existence of a local cardiac ADN regulation, independent of the circulating $\mathrm{ADN}$, as previously described in human [36,37] and murine hearts [38]. The cardiac protein expression of ADN in our samples was difficult to detect. We detected small amounts of ADN in the extracellular matrix surrounding the injured areas of the PS, but not in OS and controls. Consistent with these findings, previous studies have reported the presence of ADN in damaged regions of the heart, also due to its leakage from the vascular section [39-41]. Moreover, down-regulation of ADN mRNA expression, compared to controls, and the myocardial over-expression of AdipoR1 in PS suggested the existence of a possible feedback loop, as previously observed in skeletal muscle [35].

The mechanisms underlying this down-regulation are yet unknown. It is well-recognized that inflammatory cytokine production, particularly TNF- $\alpha$, plays a critical pathogenic role in cardiovascular complications, and a reciprocal action between TNF- $\alpha$ and ADN exists $[42,43]$. However, in our model we found that cardiac ADN was down-regulated in absence of inflammatory response. In fact, TNF- $\alpha$ at the mRNA and protein level, was unchanged in each region of failing left ventricle and no inflammatory cells were detected. Accordingly, myocardial expression of PPAR- $\gamma$, a known upstream regulator of $\mathrm{ADN}$ [2], was also unchanged in each region of the failing heart. On the other hand, Sturk et al. provided evidence, directly in cardiomyocytes, of a cardiac regulatory feedback loop in ADN expression, without identifying any specific cardiomyocyte-derived secreted factors that exert this negative feedback [36]. Otherwise, a negative relationship between ADN and BNP mRNA expression was observed in this study (Figure 3C), suggesting that impaired contractile function in the failing heart could affect the ADN/AdipoR1 system. In a recent 
study in murine hearts with transverse aortic constriction, inverse correlations between myocardial ADN and BNP as well as heparin-binding epidermal growth factor (HB-EGF) were shown, indicating an important role for $\mathrm{ADN}$ in mediating the myocardial hypertrophic signaling pathway [38]. However, in our experimental animal model, cardiac tissue did not develop hypertrophic remodeling, as shown by the collagen immunohistochemistry (Figure 3E). The lack of collagen deposits in PS in absence of coronary stenosis and inflammation suggests the occurrence of non-ischemic ventricular remodeling due to mechanical stress, which could impair the cardiac ADN/AdipoR1 system. Sen et al. [44] demonstrated in vitro that continuous mechanical strain inhibits ADN expression at the transcriptional level.

As a matter of fact, it has been suggested that ADN may directly protect cardiomyocytes [37] largely via an AMPK-mediated signal pathway [9]. However, the lack of variation of AMPK expression and activity in our animal model supports the hypothesis that other pathways drive the cardioprotection afforded by ADN. In fact, treatment with $\mathrm{ADN}$ is still effective in improving the cardiac function in AMPK knockout mice [45]. The cardioprotective action of ADN may be performed by suppression of TNF- $\alpha$ signaling via the COX-2-prostaglandin E2-linked cascade [46]. In our conditions, TNF- $\alpha$ did not show any changes between HF and controls either at mRNA or protein level (Figure 4). In addition, it has been reported that ADN might prevent excess NO generation by inhibiting iNOS expression [45]. In our model, no significant variation of iNOS expression was found in HF compared to controls and no correlation with myocardial ADN was observed.

\section{Limitations}

Other downstream ADN signalling pathways such as ceramides $[47,48]$ and other factors besides ADN that could affect the transduction signalling [49,50] exist; however, the samples collected in our study are inconsistent for their evaluation. The main limitation of this study is the impossibility of evaluating these further mechanisms involved in both ADN and AMPK signalling.

\section{Conclusions}

Our findings were observed in a reliable translational animal model of non-ischemic HF. The pacing-induced HF model is considered the gold standard in HF experimental research due to its relative similarities with many features of clinical dilated cardiomyopathy [51]. In conclusion, we observed that in spite of its high peripheral concentrations, plasma ADN did not show cardioprotective effects, confirming its role as a negative prognostic biomarker of HF. In particular, the effect of adiponectin in non-ischemic HF is AMPK-independent. These observations suggest the occurrence of novel mechanisms by which reduced cardiac ADN levels may regionally mediate the decline of cardiac function.

\section{Abbreviations}

AdipoR1: Adiponectin receptor 1; AdipoR2: Adiponectin receptor 2; ADN: Adiponectin; AMPK: AMP-activated protein kinase; BNP: Brain natriuretic peptides; DCM: Dilated cardiomiopathy; GAPDH: Glyceraldehyde 3-phosphate dehydrogenase; HF: Heart failure; HPRT-1: Hypoxanthine phosphoribosyltransferase 1; HKG: Housekeeping gene; iNOS: Inducible nitric oxide synthase; LV: Left ventricle; LVEDP: Left ventricle diastolic pressure; LVEF: Left ventricle ejection fraction; OS: Opposite site; PPAR-a: Peroxisome proliferator-activated receptor $a_{\text {; }}$ PPAR- $\gamma$ : Peroxisome proliferator-activated receptor $\gamma$; PS: Pacing site; RT-PCR: Reverse trascriptase polymerase chain reaction; TBP: TATA binding protein; T-CAD: T-cadherin; TNF-a: Tumor necrosis factor a

\section{Competing interests}

The authors declare they have no competing interests.

\section{Authors' contributions}

As to the contribution of each author, CC and DG designed the study, analyzed and interpreted the results, and drafted the manuscript; GDA and FB were involved in the animal model; MC, TP and VO made substantial contributions to performing the experimental protocol; VL, LM and SDR were involved in revising the manuscript critically for important intellectual content. All authors participated in the discussion and interpretation of the results and in the final approval of the manuscript submitted.

\section{Acknowledgements}

This work was supported by Compagnia di San Paolo, Torino, Italy; Ministero della Salute-bando giovani ricercatori (RF 2007), Italy; and Ministero Istruzione Università e Ricerca (MIUR) PRIN 2008 (2008CJ7CTW-003) and PRIN 2008 (2008KLNBBJ), Italy. The authors wish to thank Drs. B. Battolla and C. Segnani (Department of Human Morphology and Applied Biology, Medical Histology and Embryology Section, University of Pisa, Pisa, Italy) for their histological support.

\section{Author details}

${ }^{1}$ Consiglio Nazionale delle Ricerche (CNR), Institute of Clinical Physiology, Laboratory of Cardiovascular Biochemistry, Pisa, Italy. ${ }^{2}$ Department of Medicine, Scuola Superiore Sant'Anna, Pisa, Italy. ${ }^{3}$ Fondazione CNR-Regione Toscana "G. Monasterio", Pisa, Italy. ${ }^{4}$ Department of Experimental Pathology BMIE, Faculty of Medicine, University of Pisa, Pisa, Italy. ${ }^{5}$ Human Section of Histology and Medical Embryology, Department of Human Morphology and Applied Biology, University of Pisa, Pisa, Italy.

Received: 7 September 2012 Accepted: 7 November 2012 Published: 19 November 2012

\section{References}

1. Ouchi N, Walsh K: Adiponectin as an anti-inflammatory factor. Clin Chem Acta 2007, 380:24-30.

2. Ding G, Qin Q, He N, Francis-David SC, Hou J, Liu J, Ricks E, Yang Q: Adiponectin and its receptors are expressed in adult ventricular cardiomyocytes and upregulated by activation of peroxisome proliferator-activated receptor gamma. J Mol Cell Cardiol 2007, 43:73-84.

3. Cao Y, Tao L, Yuan Y, Jiao X, Lau WB, Wang Y, Christopher T, Lopez B, Chan L, Goldstein B, Ma XL: Endothelial dysfunction in adiponectin deficiency and its mechanisms involved. J Mol Cell Cardiol 2009, 46:413-419.

4. Yamauchi T, Kamon J, Ito Y, Tsuchida A, Yokomizo T, Kita S, Christopher T, Lopez B, Chan L, Goldstein B, Ma XL: Cloning of adiponectin receptors that mediate antidiabetic metabolic effects. Nature 2003, 423:762-769.

5. Denzel MS, Scimia MC, Zumstein PM, Walsh K, Ruiz-Lozano P, Ranscht B: T-cadherin is critical for adiponectin-mediated cardioprotection in mice. J Clin Invest 2010, 120:4342-4352.

6. Lionetti V, Stanley WC, Recchia FA: Modulating fatty acid oxidation in heart failure. Cardiovasc Res 2011, 90:202-209. 
7. Kadowaki T, Yamauchi T: Adiponectin and adiponectin receptors. Endocr Rev 2005, 26:439-451.

8. Katagiri H, Yamada T, Oka Y: Adiposity and cardiovascular disorders: disturbance of the regulatory system consisting of humoral and neuronal signals. Cir Res 2007, 101:27-39.

9. Shibata R, Sato K, Pimentel DR, Takemura Y, Kihara S, Ohashi K, Funahashi T, Ouchi N, Walsh K: Adiponectin protects against myocardial ischemia-reperfusion injury through AMPK- and COX-2-dependent mechanism. Nat Med 2005, 11:1096-1103.

10. Giannessi D, Maltinti M, Del Ry S: Adiponectin circulating levels: a new emerging biomarker of cardiovascular risk. Pharmacol Res 2007, 56:459-467.

11. Goldstein BJ, Scalia RG, Ma XL: Protective vascular and myocardial effects of adiponectin. Nat Clin Pract Cardiovasc Med 2009, 6:27-35.

12. Kumada M, Kihara S, Sumitsuji S, Kawamoto T, Matsumoto S, Ouchi N, Arita Y, Okamoto Y, Shimomura I, Hiraoka H, Nakamura T, Funahashi T, Matsuzawa Y, Osaka CAD Study Group: Coronary artery disease. Association of hypoadiponectinemia with coronary artery disease in men. Arterioscler Thromb Vasc Biol 2003, 23:85-89.

13. Nakamura $Y$, Shimada $K$, Fukuda D, Shimada $Y$, Ehara S, Hirose M, Kataoka T, Kamimori K, Shimodozono S, Kobayashi Y, Yoshiyama M, Takeuchi K, Yoshikawa J: Implications of plasma concentrations of adiponectin in patients with coronary artery disease. Heart 2004, 90:528-533.

14. Maahs DM, Ogden LG, Kinney GL, Wadwa P, Snell-Bergeon JK, Dabelea D, Hokanson JE, Ehrlich J, Eckel RH, Rewers M: Low plasma adiponectin levels predict progression of coronary artery calcification. Circulation 2005, 111:747-753.

15. von Eynatten M, Humpert PM, Bluemm A, Lepper PM, Hamann A, Allolio B, Nawroth PP, Bierhaus A, Dugi KA: High-molecular weight adiponectin is independently associated with the extent of coronary artery disease in men. Atherosclerosis 2008, 199:123-128.

16. Kollias A, Tsiotra PC, Ikonomidis I, Maratou E, Mitrou P, Kyriazi E, Boutati E, Lekakis J, Economopoulos T, Kremastinos DT, Dimitriadis G, Raptis SA: Adiponectin levels and expression of adiponectin receptors in isolated monocytes from overweight patients with coronary artery disease. Cardiovasc Diabetol 2011, 1:10-14.

17. Chen WJ, Rijzewijk LJ, van der Meer RW, Heymans MW, van Duinkerken E, Lubberink M, Lammertsma AA, Lamb HJ, de Roos A, Romijn JA, Smit JW, Bax JJ, Bjerre M, Frystyk J, Flyvbjerg A, Diamant M: Association of plasma osteoprotegerin and adiponectin with arterial function, cardiac function and metabolism in asymptomatic type 2 diabetic men. Cardiovasc Diabetol 2011, 19:10-67.

18. Giannessi D, Caselli C, Del Ry S, Maltinti M, Pardini S, Turchi S, Cabiati M, Sampietro T, Abraham N, L'abbate A, Neglia D: Adiponectin is associated with abnormal lipid profile and coronary microvascular dysfunction in patients with dilated cardiomyopathy without overt heart failure. Metabolism 2011, 60:227-233.

19. Tsutamoto T, Tanaka T, Sakai H, Ishikawa C, Fujii M, Yamamoto T, Horie M: Total and high molecular weight adiponectin, haemodynamics, and mortality in patients with chronic heart failure. Eur Heart J 2007, 28:1723-1730.

20. Kistorp C, Faber J, Galatius S, Gustafsson F, Frysryk J, Flyvbjerg A, Hildebrandt P: Plasma adiponectin, body mass index, and mortality in patients with chronic heart failure. Circulation 2005, 112:1756-1762.

21. Kintscher U: Does adiponectin resistance exist in chronic heart failure? Eur Heart J 2007, 28:1676-1677

22. Lionetti V, Guiducci L, Simioniuc A, Aquaro GD, Simi C, De Marchi D, Burchielli S, Pratali L, Piacenti M, Lombardi M, Salvadori P, Pingitore A, Neglia D, Recchia FA: Mismatch between uniform increase in cardiac glucose uptake and regional contractile dysfunction in pacing-induced heart failure. Am J Physiol Heart Circ Physiol 2007, 293:2747-2756.

23. Lionetti V, Aquaro GD, Simioniuc A, Di Cristofano C, Forini F, Cecchetti F, Campan M, De Marchi D, Bernini F, Grana M, Nannipieri M, Mancini M, Lombardi M, Recchia FA, Pingitore A: Severe mechanical dyssynchrony causes regional hibernation-like changes in pigs with nonischemic heart failure. J Card Fail 2009, 15:920-928.

24. Prinzen FW, Hunter WC, Wyman BT, McVeigh ER: Mapping of regional myocardial strain and work during ventricular pacing: experimental study using magnetic resonance imaging tagging. J Am Coll Cardiol 1999, 33:1735-1742.
25. Del Ry S, Cabiati M, Lionetti V, Simioniuc A, Caselli C, Prescimone T, Emdin M, Giannessi D: Asymmetrical myocardial expression of natriuretic peptides in pacing-induced heart failure. Peptides 2009, 30:1710-1713.

26. Martino A, Cabiati M, Campan M, Prescimone T, Minocci D, Caselli C, Rossi AM, Giannessi D, Del Ry S: Selection of reference genes for normalization of real time PCR data in minipig heart failure model and evaluation of TNF alpha mRNA expression. J Biotechnol 2011, 153:92-99.

27. Vandesompele J, De Preter K, Pattyn F, Poppe B, Van Roy N, De Paepe A, Speleman F: Accurate normalization of real-time quantitative RT-PCR data by geometric averaging of multiple internal control genes. Genome Biol 2002, 3:RESEARCH0034.

28. Takano H, Obata J, Kodama Y, Kitta Y, Nakamura T, Mende A, Kawabata K, Saito Y, Fujioka D, Kobayashi T, Yano T, Sano K, Kugiyama K: Adiponectin is released from the heart in patients with heart failure. Int J Cardiol 2009, 20:221-226

29. Tsukamoto O, Fujita M, Kato M, Yamazaki S, Asano Y, Ogai A, Okazaki H, Asai M, Nagamachi Y, Maeda N, Shintani Y, Minamino T, Asakura M, Kishimoto I, Funahashi T, Tomoike H, Kitakaze M: Natriuretic peptides enhance the production of adiponectin in human adipocytes and in patients with chronic heart failure. J Am Coll Cardiol 2009, 53:2070-2077.

30. Tanaka K, Tsutamoto T, Sakai H, Nishivama K, Fujii M, Yamamoto T, Horie M: Effect of atrial natriuretic peptide on adiponectin in patients with heart failure. Eur J Heart Fail 2008, 10:360-366.

31. Stanek B, Frey B, Hülsmann M, Berger R, Sturm B, Strametz-Juranek J, Bergler-Klein J, Moser P, Bojic A, Hartter E, Pacher R: Prognostic evaluation of neurohumoral plasma levels before and during beta-blocker therapy in advanced left ventricular dysfunction. J Am Coll Cardiol 2001, 38:436-442.

32. McEntegart MB, Awede B, Petrie MC, Sattar N, Dunn FG, MacFarlane NG, McMurray JJ: Increase in serum adiponectin concentration in patients with heart failure and cachexia: relationship with leptin, other cytokines, and B-type natriuretic peptide. Eur Heart J 2007, 28:829-835.

33. Lau CH, Muniandy S: Novel adiponectin-resistin (AR) and insulin resistance (IRAR) indexes are useful integrated diagnostic biomarkers for insulin resistance, type 2 diabetes and metabolic syndrome: a case control study. Cardiovasc Diabetol 2011, 21(10(1)):8.

34. Mamas MA, Deaton C, Rutter MK, Yuille M, Williams SG, Ray SG, New J, Gibson JM, Neyses L: Impaired glucose tolerance and insulin resistance in heart failure: under-recognized and under-treated? J Card Fail 2010, 16:761-768.

35. Van Berendoncks AM, Garnier A, Beckers P, Hoymans VY, Possemiers $N$ Fortin D, Martinet W, Van Hoof V, Vrints CJ, Ventura-Clapier R, Conraads VM: Functional adiponectin resistance at the level of the skeletal muscle in mild to moderate chronic heart failure. Circ Heart Fail 2010, 3:185-194.

36. Skurk C, Wittchen F, Suckau L, Witt H, Noutsias M, Fechner H, Schultheiss HP, Poller W: Description of a local cardiac adiponectin system and its deregulation in dilated cardiomyopathy. Eur Heart J 2008, 29:1168-1180.

37. Wittchen F, Suckau L, Witt H, Skurk C, Lassner D, Fechner H, Sipo I, Ungethüm U, Ruiz P, Pauschinger M, Tschope C, Rauch U, Kühl U, Schultheiss HP, Poller W: Genomic expression profiling of human inflammatory cardiomyopathy (DCMi) suggests novel therapeutic targets. J Mol Med 2007, 85:257-271.

38. Liao Y, Xuan W, Zhao J, Bin J, Zhao H, Asakura M, Funahashi T, Takashima S, Kitakaze M: Antihypertrophic effects of adiponectin on cardiomyocytes are associated with the inhibition of heparin-binding epidermal growth factor signaling. Bioch Biophy Res Com 2010, 393:519-525.

39. Shibata R, Izumiya Y, Sato K, Papanicolaou K, Kihara S, Colucci WS, Sam F, Ouchi N, Walsh K: Adiponectin protects against the development of systolic dysfunction following myocardial infarction. I Mol Cell Cardiol 2007, 42:1065-1074.

40. Kondo K, Shibata R, Unno K, Shimano M, Ishii M, Kito T, Shintani S, Walsh K, Ouchi N, Murohara T: Impact of a single intracoronary administration of adiponectin on myocardial ischemia/reperfusion injury in a pig model. Circ Cardiovasc Interv 2010, 3:166-173.

41. Okamoto Y, Arita Y, Nishida M, Muraguchi M, Ouchi N, Takahashi M, Igura T, Inui Y, Kihara S, Nakamura T, Yamashita S, Miyagawa J, Funahashi T, Matsuzawa Y: An adipocyte-derived plasma protein, adiponectin, adheres to injured vascular walls. Horm Metab Res 2000, 32:47-50.

42. Li R, Wang WQ, Zhang H, Yang X, Fan Q, Christopher TA, Lopez BL, Tao L, Goldstein BJ, Gao F, Ma XL: Reduced vascular responsiveness to 
adiponectin in hyperlipidemic rats-mechanisms and significance. $J \mathrm{Mol}$ Cell Cardiol 2010, 49:508-515.

43. Liu S, Yin T, Wei X, Yi W, Qu Y, Liu Y, Wang R, Lian K, Xia C, Pei H, Sun L, Ma Y, Lau WB, Gao E, Koch WJ, Wang H, Tao L: Downregulation of adiponectin induced by tumor necrosis factor $a$ is involved in the aggravation of posttraumatic myocardial ischemia/reperfusion injury. Crit Care Med 2011, 39:1935-1943.

44. Sen B, Xie Z, Case N, Ma M, Rubin C, Rubin J: Mechanical strain inhibits adipogenesis in mesenchymal stem cells by stimulating a durable beta-catenin signal. Endocrinology 2008, 149:6065-6075.

45. Wang Y, Gao E, Tao L, Lau WB, Yuan Y, Goldstein BJ, Lopez BL, Christopher TA, Tian R, Koch W, Ma XL: AMP-activated protein kinase deficiency enhances myocardial ischemia/reperfusion injury but has minimal effect on the antioxidant/antinitrative protection of adiponectin. Circulation 2009, 119:835-844.

46. Ikeda Y, Ohashi K, Shibata R, Pimentel DR, Kihara S, Ouchi N, Walsh K: Cyclooxygenase-2 induction by adiponectin is regulated by a sphingosine kinase-1 dependent mechanism in cardiac myocytes. FEBS Lett 2008, 582:1147-1150.

47. Holland WL, Miller RA, Wang ZV, Sun K, Barth BM, Bui HH, Davis KE, Bikman BT, Halberg N, Rutkowski JM, Wade MR, Tenorio VM, Kuo MS, Brozinick JT, Zhang BB, Birnbaum MJ, Summers SA, Scherer PE: Receptor-mediated activation of ceramidase activity initiates the pleiotropic actions of adiponectin. Nat Med 2011, 17:55-63.

48. Kadowaki T, Yamauchi T: Adiponectin receptor signaling: a new layer to the current model. Cell Metab 2011, 13:123-124.

49. Beauloye C, Bertrand L, Horman S, Hue L: AMPK activation, a preventive therapeutic target in the transition from cardiac injury to heart failure. Cardiovasc Res 2011, 90:224-233.

50. Towler MC, Hardie DG: AMP-activated protein kinase in metabolic control and insulin signaling. Circ Res 2007, 16:328-341.

51. Dixon JA, Spinale FG: Large animal models of heart failure: a critical link in the translation of basic science to clinical practice. Circ Heart Fail 2009, 2:262-271.

doi:10.1186/1475-2840-11-143

Cite this article as: Caselli et al:: Regional evidence of modulation of cardiac adiponectin level in dilated cardiomyopathy: pilot study in a porcine animal model. Cardiovascular Diabetology 2012 11:143.

\section{Submit your next manuscript to BioMed Central and take full advantage of:}

- Convenient online submission

- Thorough peer review

- No space constraints or color figure charges

- Immediate publication on acceptance

- Inclusion in PubMed, CAS, Scopus and Google Scholar

- Research which is freely available for redistribution 